\title{
Treatment strategy and outcomes in locally advanced head and neck squamous cell carcinoma: a nationwide retrospective cohort study (KCSG HN13-01)
}

Yun-Gyoo Lee ${ }^{1 \dagger}$, Eun Joo Kang ${ }^{2 \dagger}$, Bhumsuk Keam ${ }^{3 *}$, Jin-Hyuk Choi ${ }^{4}$, Jin-Soo Kim ${ }^{5}$, Keon Uk Park ${ }^{6}$, Kyoung Eun Lee ${ }^{7}$, Jung Hye Kwon ${ }^{8}$, Keun-Wook Lee ${ }^{9}$, Min Kyoung Kim ${ }^{10}$, Hee Kyung Ahn ${ }^{11}$, Seong Hoon Shin ${ }^{12}$, Hye Ryun Kim ${ }^{13}$, Sung-Bae Kim ${ }^{14}$ and Hwan Jung Yun ${ }^{15^{*}}$

\begin{abstract}
Background: By investigating treatment patterns and outcomes in locally advanced head and neck squamous cell carcinoma (LA-HNSCC), we aimed at providing valuable insights into the optimal therapeutic strategy for physicians in real-world practice.

Methods: This is a multi-institutional study enrolled the patients with stage III to IVB LA-HNSCC, except for nasopharyngeal carcinoma, from 2004 to 2015 in thirteen referral hospitals capable of multidisciplinary care.

Results: A total of 445 LA-HNSCC patients were analyzed. The median age was 61 years (range, 24-89). The primary tumor location was the oropharynx in 191 (43\%), oral cavity in 106 (24\%), hypopharynx in 64 (14\%), larynx in 57 (13\%) and other sites in 27 (6\%). The most common stage was T2 in 172 (39\%), and N2 in 245 (55\%). Based on treatment intents, 229 (52\%) of the patients received definitive concurrent chemoradiotherapy (CCRT) and 187 (42\%) underwent surgery. Approximately 158 (36\%) of the study population received induction chemotherapy (IC). Taken together, 385 (87\%) of the patients underwent combined therapeutic modalities. The regimen for definitive CCRT was weekly cisplatin in 58\%, 3-weekly cisplatin in $28 \%$ and cetuximab in $3 \%$. The preferred regimen for IC was docetaxel with cisplatin in $49 \%$, and docetaxel, cisplatin plus fluorouracil in $27 \%$. With a median follow-up of 39 months, one-year and two-year survival rates were 89 and $80 \%$, respectively. Overall survival was not significantly different between CCRT and surgery group $(p=0.620)$.
\end{abstract}

Conclusions: In patients with LA-HNSCC, the majority of patients received combined therapeutic modalities. Definitive CCRT, IC then definitive CCRT, and surgery followed by adjuvant CCRT or radiotherapy are the preferred multidisciplinary strategies in real-world practice.

Keywords: Locally advanced head and neck cancer, Squamous cell carcinoma, Multidisciplinary treatment, Strategy

\footnotetext{
* Correspondence: bhumsuk@snu.ac.kr; hjyun@cnuh.co.kr

${ }^{\dagger}$ Yun-Gyoo Lee and Eun Joo Kang contributed equally to this work.

${ }^{3}$ Department of Internal Medicine, Seoul National University Hospital, 101 Daehak-ro, Jongno-gu, Seoul 03080, Republic of Korea

${ }^{15}$ Department of Internal Medicine, Chungnam National University Hospital,

282 Munhwa-ro, Jung-gu, Daejeon 35015, Republic of Korea

Full list of author information is available at the end of the article
}

(C) The Author(s). 2020 Open Access This article is licensed under a Creative Commons Attribution 4.0 International License, which permits use, sharing, adaptation, distribution and reproduction in any medium or format, as long as you give appropriate credit to the original author(s) and the source, provide a link to the Creative Commons licence, and indicate if changes were made. The images or other third party material in this article are included in the article's Creative Commons licence, unless indicated otherwise in a credit line to the material. If material is not included in the article's Creative Commons licence and your intended use is not permitted by statutory regulation or exceeds the permitted use, you will need to obtain permission directly from the copyright holder. To view a copy of this licence, visit http://creativecommons.org/licenses/by/4.0/ The Creative Commons Public Domain Dedication waiver (http://creativecommons.org/publicdomain/zero/1.0/) applies to the data made available in this article, unless otherwise stated in a credit line to the data. 


\section{Background}

Head and neck squamous cell carcinoma (HNSCC) and its associated variants originate from multiple anatomic subsites in the oral cavity, oropharynx, hypopharynx and larynx. Given the heterogeneous biology of HNSCC at each subsite, treatments are complex. Generally, the primary tumor location, stage of tumor and lymph node, and pathologic characteristics guide specialized treatments including surgical procedures, radiotherapy, and/or systemic chemotherapy [1].

Around $40 \%$ of patients with HNSCC present with limited or early-stage disease, in which treatment is ordinarily single modality, either surgery or radiotherapy $[2,3]$. The locally advanced (LA) HNSCC comprises the remaining $60 \%$ of patients, whom multidisciplinary modal therapy is generally recommended with either surgery followed by postoperative radiotherapy or chemoradiotherapy (CCRT), or definitive CCRT [1, 3]. Despite decades of research in the area of LA-HNSCC treatment, the clinical significance of induction chemotherapy (IC) has not been conclusive [4]. Regarding multimodal approaches for HNSCC treatment, therapeutic strategies in clinical practice depend on a multidisciplinary team approach at each hospital $[1,5]$. The most effective treatment modality has yet to be established.

We describe the real-world patterns for the initial treatment of LA-HNSCC in a large nationwide cohort treated with multidisciplinary treatment modalities. By studying this population, in which patients received multidisciplinary treatment, we aim to provide valuable insights regarding the optimal therapeutic strategy for physicians.

\section{Methods}

\section{Patients}

This study enrolled 445 patients who were pathologically confirmed with LA-HNSCC between January 2005 and December 2015 at 13 tertiary referral hospitals located in the Republic of Korea. All the participating hospitals have their own multidisciplinary team for head and neck cancer with specialists.

LA-HNSCC was defined as clinical stage III to IVB based on the 7th edition of the American Joint Committee on Cancer [6]. Adults patients aged 20 years or older with primary squamous cell carcinoma of oropharynx, hypopharynx, larynx, oral cavity, or nasal cavity were included for analysis. Patients with biopsy-proven squamous cell carcinoma at the cervical lymph node without known origin were regarded to be of head and neck origin and were also included in this study. HPV positivity based on the results from either HPV DNA by real-time PCR or p16 expression by immunohistochemistry, depending on availability in each participating institution.

We excluded patients with nasopharyngeal cancer which differs from other HNSCC in its epidemiology, pathology, natural history and treatment, patients with distant metastasis at initial diagnosis and patients with a previous secondary malignancy diagnosed within 3 years of HNSCC diagnosis. The Institutional Review Board for main hospital (IRB-H-1304-089-481) and each participating hospital approved this study. Medical records were retrospectively reviewed for patients who were diagnosed with LA-HNSCC.

\section{Multidisciplinary treatment}

In principle, all patients were treated according to specific treatment protocols established at each participating hospital. The treatment modality, including surgery, chemotherapy, and radiotherapy, was decided according to a multidisciplinary team approach of each hospital. When the opinions disagreed between each discipline, the agreed recommendations of the multidisciplinary care team were followed. IC is defined as chemotherapy which facilitates subsequent local therapy such as definitive CCRT or surgery. Inadequate treatment group was defined as patients who did not receive subsequent definitive treatment after diagnosis because of patient's refusal or intolerance. All imaging studies, including MRI or CT of the head and neck, were assessed, as well as chest CT, abdominal CT, brain MRI, or positron emission tomography/CT scans where available, obtained when there were specific symptoms or clinical suspicion. Follow-up imaging was performed based on the protocol of each hospital.

\section{Study outcomes}

The primary outcome was to identify treatment patterns that are being performed in real-world practice for the treatment of LA-HNSCC. The secondary outcome was to compare progression-free survival (PFS) and overall survival (OS) by treatment strategy and/or primary site. PFS was defined as time from diagnostic date of HNSCC until disease recurrence, progression by RECIST criteria or death of any cause. OS was defined as time from date of diagnosis to death, regardless of cause.

\section{Statistical analysis}

Chi-square tests and independent $\mathrm{t}$-tests were used to compare categorical and continuous variables between groups, as appropriate. Multivariate Cox regression analysis was used for PFS and OS. Statistical significance was set at a two-sided $P$-value $<0.05$. All statistical analyses were performed using Stata 16.0 software (Stata Corp LP, College Station, TX, USA).

\section{Results}

\section{Patient characteristics}

A total of 445 patients with LA-HNSCC were enrolled in this study and analyzed retrospectively. The median age was 61 years (range, 24-89), and 385 (87\%) were 
male. The primary tumor location was the oropharynx in 191 (43\%) of the cases, followed by oral cavity in 106 (24\%), hypopharynx in 64 (14\%), larynx in $57(13 \%)$, and other sites in 27 (6\%). Other sites included maxillary sinus, nasal cavity, ethmoid sinus, and unknown primary squamous carcinoma. The most common clinical tumor (T) and lymph node (N) stage was T2 in $172(39 \%)$ and N2 in 245 (55\%), respectively. About 58\% (256) of study patients was unknown for HPV infection. Of 189 patients who were tested for HPV status, 48\% (90/189) were positive. Table 1 summarized the demographics of study population.

\section{Treatment strategy}

Based on treatment intents, patients received definitive CCRT in 229 (52\%) of cases and surgery in 187 (42\%). The remaining 29 (7\%) did not receive adequate treatment. Approximately 158 (36\%) of the study population received IC. In 229 patients from the CCRT group, 45\% (103 patients) underwent IC prior to definitive CCRT. In 187 patients from the surgery group, 17\% (32 patients) received IC followed by surgery with curative intent. Of the 29 patients in the inadequate treatment group, about $80 \%(23 / 29)$ failed to receive subsequent treatment after IC. Taken together, 385 (87\%) of the patients were treated with combined treatment modalities (Fig. 1).

\section{Treatment characteristics}

Details of the treatment modalities are shown in Table 2. For 158 patients receiving IC, the preferred regimen was DP (docetaxel and cisplatin) in $49 \%(77 / 158)$ of the patients, TPF (docetaxel, cisplatin and fluorouracil) in $27 \%$ (42/158), FP (Fluorouracil and cisplatin) in 18\% $(28 / 158)$, and other therapies in $7 \%(11 / 158)$. The median number of cycles for chemotherapy was 3 (range $1-5)$. The best overall response was a complete response (CR) in $16 \%(25 / 158)$, a partial response (PR) in 55\% $(87 / 158)$, stable disease (SD) in $20 \%(31 / 158)$ and progressive disease $(\mathrm{PD})$ in $10 \%(15 / 158)$ of the patients. Patients presenting a good performance status were more likely to receive IC compared with those with a poor performance status $(p<0.001)$. For oropharyngeal and hypopharyngeal cancer, patients received IC more frequently compared with those in the oral cavity and larynx group $(p<0.001)$. For clinical T and $\mathrm{N}$ classification, patients presenting advanced stage $\mathrm{T}$ and $\mathrm{N}$ were more likely to receive IC $(p<0.001$, Supplementary Table 1).

Of the 305 patients receiving CCRT, the goal was to treat $75 \%(229 / 305)$ with definitive and 24\% (76/305) with adjuvant therapy. The preferred regimen for definitive CCRT was weekly cisplatin for $58 \%$, 3-weekly cisplatin for $28 \%$, and 5 -fluorouracil and cisplatin for $10 \%$ of the patients. Cetuximab was selected for only $3 \%$ of the patients. The median dose of irradiation was $67.5 \mathrm{~Gy}$ (range 32-72). The best overall response was a CR in $65 \%$, PR in $19 \%$, SD in $9 \%$, and PD in $7 \%$. The CCRT regimen was not different between the definitive and adjuvant setting ( $p=0.151$, unpublished data).

\section{Study outcomes}

With a median follow-up period of 39.3 months (95\% CI 35.4-43.1), 113 deaths were observed. For 445 patients, 1-year and 2-year survival rates were $88.7 \%$ (95\% CI 85.2-91.3) and 79.8\% (95\% CI 75.4-83.4), respectively. A median OS was not reached. When drawing a flowchart with respect to treatment intent, $52 \%(229 / 445)$ of the patients received definitive CCRT, and 42\% (187/445) underwent surgery. The most frequently adopted treatment strategy was definitive CCRT in 28\% (126/445), IC followed by definitive CCRT in 23\% (103/445), and surgery followed by adjuvant CCRT or radiotherapy in $14 \%$ (63/445) (Fig. 1).

When comparing survival probabilities between the CCRT and surgery groups, OS was not significantly different (HR 0.90; 95\% CI 0.61-1.35; $p=0.620$ ) (Fig. 2a). When patients failed to receive adequate treatment following IC or refused anticancer treatment, OS was the poorest (Fig. 2a). To evaluate the clinical role of IC, we analyzed the prognostic impact of IC in the CCRT and surgery groups. In the CCRT group, survival probabilities were not significantly different by administration of IC (HR 0.99; 95\% 0.57-1.73; $p=0.973$ ) (Fig. 2b). In the surgery group, however, patients receiving IC prior to surgery exhibited inferior OS (HR, 1.96; 95\% CI, 1.00-3.86; $p=0.05$ ) (Fig. 2c). After adjustment of covariate, the estimates of IC in surgery group was not statistically significant (HR 1.48; 95\% CI $0.58-3.82 ; p=0.423$ ). According to the primary tumor location, patients with oropharyngeal cancer showed better survival probability than non-oropharyngeal cancer (HR 0.65; 95\% CI 0.44$0.96, p=0.029$ ) (Fig. 2d, e). Compared with other primary tumor locations, oral cavity cancer showed the worst survival outcome (Fig. 2D). In oral cavity cancer, the surgical approach exhibited better survival probability than CCRT (HR 0.43; 95\% CI 0.21-0.86; $p=0.017$ ) (Fig. 2f).

\section{Multivariate analyses for PFS and OS}

Multivariate analyses for PFS revealed that primary tumor location of other sites (maxillary sinus, nasal cavity, ethmoid sinus, and unknown primary squamous carcinoma versus oropharyngeal cancer), advanced $\mathrm{T}$ classification (from one unit to the next), and inadequate treatment (vs. CCRT) were significant predictors for PFS (Table 3, Supplementary Table 2).

With respect to mortality, HPV positivity (vs. negative) was an independent prognostic indicator for improved survival. Primary tumor location in the oral cavity (vs. 
Table 1 Baseline characteristics of locally advanced head \& neck squamous cell carcinoma

\begin{tabular}{|c|c|c|c|c|c|}
\hline \multirow[t]{2}{*}{ Characteristics } & \multicolumn{2}{|l|}{ Treatment Strategy } & \multirow[t]{2}{*}{$p$-value* } & \multirow[b]{2}{*}{$\begin{array}{l}\text { Inadequate } \operatorname{Tx} \boldsymbol{n}=29 \\
(6.5 \%)\end{array}$} & \multirow[b]{2}{*}{$\begin{array}{l}\text { Total } \boldsymbol{N}=445 \\
(100 \%)\end{array}$} \\
\hline & $\begin{array}{l}\text { CCRT group } \boldsymbol{n}=229 \\
(51.5 \%)\end{array}$ & $\begin{array}{l}\text { Surgery group } \boldsymbol{n}=187 \\
(42.0 \%)\end{array}$ & & & \\
\hline Age, median [range], years & 61 [30-81] & 60 [24-89] & 0.633 & 67 [36-82] & 61 [24-89] \\
\hline Gender & & & 0.125 & & \\
\hline Female & $25(41.7 \%)$ & $30(50.0 \%)$ & & $5(8.3 \%)$ & 60 (100\%) \\
\hline Male & 204 (53.0\%) & 157 (40.8\%) & & $24(6.2 \%)$ & 385 (100\%) \\
\hline ECOG PS & & & $<0.001$ & & \\
\hline 0 & $40(72.7 \%)$ & $9(16.4 \%)$ & & $6(10.9 \%)$ & $55(100 \%)$ \\
\hline 1 & $153(71.2 \%)$ & $47(21.9 \%)$ & & $15(7.0 \%)$ & $215(100 \%)$ \\
\hline 2 & $12(70.6 \%)$ & $3(17.7 \%)$ & & $2(11.8 \%)$ & $17(100 \%)$ \\
\hline 3 & $4(100 \%)$ & $0(0.0 \%)$ & & $0(0.0 \%)$ & $4(100 \%)$ \\
\hline Unknown & $20(13.0 \%)$ & $128(83.1 \%)$ & & $6(3.9 \%)$ & $154(100 \%)$ \\
\hline Smoking history & & & $<0.001$ & & \\
\hline Never & 37 (37.4\%) & $54(54.6 \%)$ & & $8(8.1 \%)$ & $99(100 \%)$ \\
\hline Former & $62(46.3 \%)$ & $62(46.3 \%)$ & & $10(7.5 \%)$ & $134(100 \%)$ \\
\hline Current & $53(49.5 \%)$ & $46(43.0 \%)$ & & $8(7.5 \%)$ & 107 (100\%) \\
\hline Unknown & 77 (73.3\%) & $25(23.8 \%)$ & & $3(2.9 \%)$ & $105(100 \%)$ \\
\hline Alcohol history & & & $<0.001$ & & \\
\hline Do not drink & 49 (40.8\%) & $60(50.0 \%)$ & & $11(9.2 \%)$ & $120(100 \%)$ \\
\hline Drink alcohol & 71 (43.6\%) & $83(50.9 \%)$ & & $9(5.5 \%)$ & $163(100 \%)$ \\
\hline Unknown & $109(67.3 \%)$ & $44(27.2 \%)$ & & $9(5.6 \%)$ & $162(100 \%)$ \\
\hline Primary tumor location & & & $<0.001$ & & \\
\hline Oropharynx & $105(55.0 \%)$ & $73(38.2 \%)$ & & $13(6.8 \%)$ & $191(100 \%)$ \\
\hline Oral cavity & $30(28.3 \%)$ & 70 (66.0\%) & & $6(5.7 \%)$ & $106(100 \%)$ \\
\hline Hypopharynx & $42(65.5 \%)$ & $16(25.0 \%)$ & & $6(9.4 \%)$ & $64(100 \%)$ \\
\hline Larynx & 31 (54.4\%) & $24(42.1 \%)$ & & $2(3.5 \%)$ & $57(100 \%)$ \\
\hline Others & $21(77.8 \%)$ & $4(14.8 \%)$ & & $2(7.4 \%)$ & $27(100 \%)$ \\
\hline Histologic grade & & & $<0.001$ & & \\
\hline Well differentiated & $22(32.4 \%)$ & $41(60.3 \%)$ & & $5(7.4 \%)$ & $68(100 \%)$ \\
\hline Moderate differentiated & $58(36.5 \%)$ & $97(61.0 \%)$ & & $4(2.5 \%)$ & $159(100 \%)$ \\
\hline Poorly differentiated & $42(63.6 \%)$ & $21(31.8 \%)$ & & $3(4.6 \%)$ & $66(100 \%)$ \\
\hline Not assessed & $107(70.4 \%)$ & $28(18.8 \%)$ & & $17(11.4 \%)$ & $152(100 \%)$ \\
\hline T classification & & & $<0.001$ & & \\
\hline $\mathrm{T} 1$ & $21(31.8 \%)$ & $43(65.2 \%)$ & & $2(3.0 \%)$ & $66(100 \%)$ \\
\hline $\mathrm{T} 2$ & $85(49.4 \%)$ & $80(46.5 \%)$ & & $7(4.1 \%)$ & $172(100 \%)$ \\
\hline $\mathrm{T} 3$ & $57(60.6 \%)$ & $30(31.9 \%)$ & & $7(7.5 \%)$ & $94(100 \%)$ \\
\hline $\mathrm{T} 4 \mathrm{a} / \mathrm{T} 4 \mathrm{~b}$ & $51 / 14(58.6 \%)$ & 31 / 2 (29.7\%) & & $11 / 2(11.7 \%)$ & $93 / 18$ (100\%) \\
\hline Unknown & $1(50.0 \%)$ & $1(50.0 \%)$ & & $0(0.0 \%)$ & $2(100 \%)$ \\
\hline N classification & & & $<0.001$ & & \\
\hline No & $25(48.1 \%)$ & $24(46.2 \%)$ & & $3(5.8 \%)$ & $52(100 \%)$ \\
\hline N1 & $56(40.0 \%)$ & 79 (56.4\%) & & $5(3.6 \%)$ & 140 (100\%) \\
\hline N2 & $142(58.0 \%)$ & $83(33.9 \%)$ & & $20(8.2 \%)$ & $245(100 \%)$ \\
\hline N3 & $6(85.7 \%)$ & $1(14.3 \%)$ & & $0(0.0 \%)$ & $7(100 \%)$ \\
\hline Unknown & $0(0.0 \%)$ & $0(0.0 \%)$ & & $1(100 \%)$ & $1(100 \%)$ \\
\hline P16/HPV status & & & $<0.001$ & & \\
\hline Negative & $16(16.2 \%)$ & 79 (79.8\%) & & $4(4.0 \%)$ & $99(100 \%)$ \\
\hline Positive & $45(50.0 \%)$ & $43(47.8 \%)$ & & $2(2.2 \%)$ & $90(100 \%)$ \\
\hline Unknown & 168 (65.6\%) & 65 (25.4\%) & & $23(9.0 \%)$ & 256 (100\%) \\
\hline
\end{tabular}




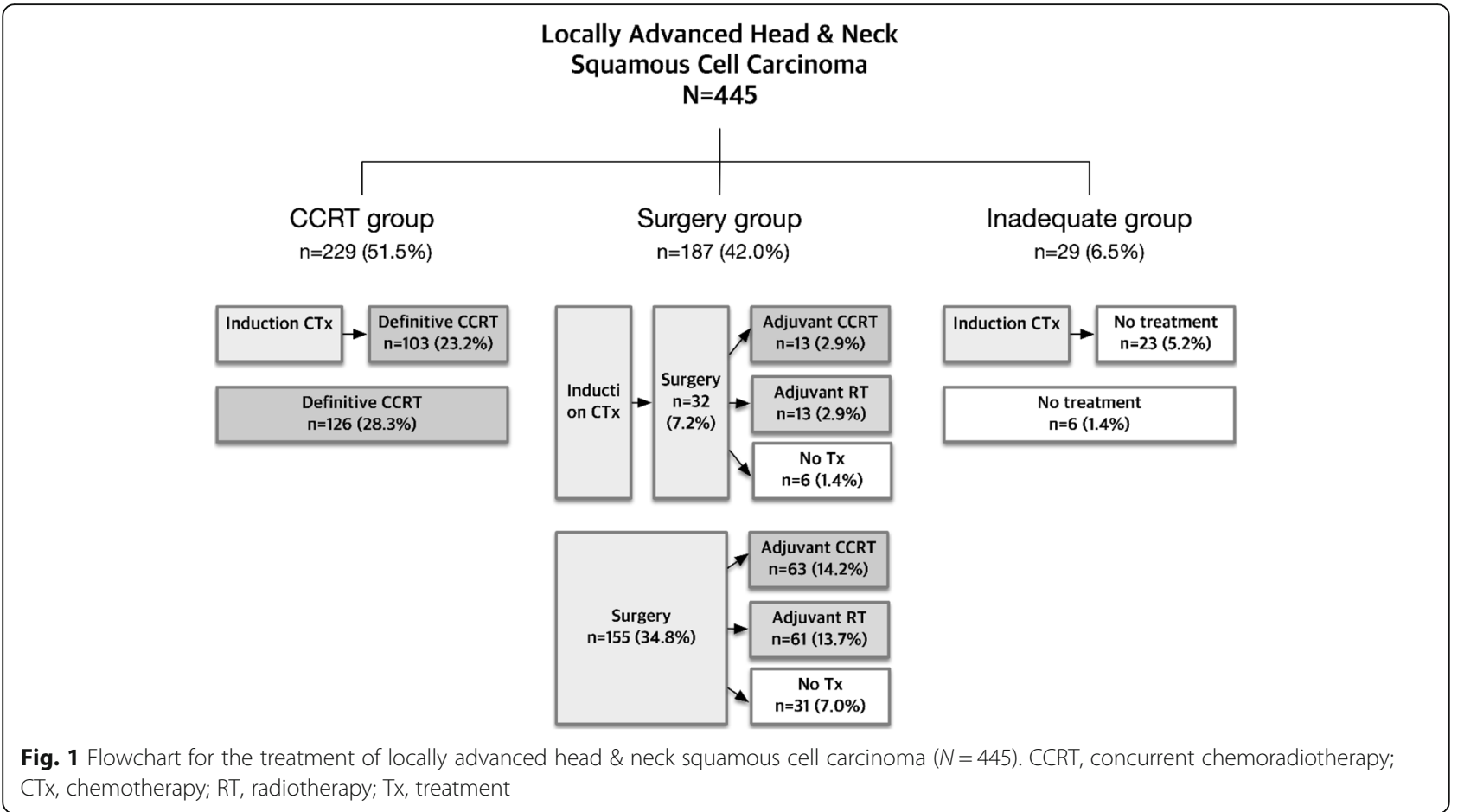

Table 2 Characteristics of treatment modalities in patients with LA-HNSCC

\begin{tabular}{|c|c|c|}
\hline Treatment & & Number (\%) \\
\hline $\begin{array}{l}\text { Induction } \\
\text { chemotherapy }\end{array}$ & & $n=158$ \\
\hline \multirow[t]{4}{*}{ Regimen } & Docetaxel + Cisplatin & 77 (48.7\%) \\
\hline & $\begin{array}{l}\text { Docetaxel + Cisplatin + } \\
\text { Fluorouracil }\end{array}$ & $42(26.6 \%)$ \\
\hline & Fluorouracil + Cisplatin & $28(17.7 \%)$ \\
\hline & Others & $11(7.0 \%)$ \\
\hline Number of cycles & Median: 3 cycles & Range $1-5$ \\
\hline \multirow[t]{4}{*}{ Best overall response } & Complete response & $25(15.8 \%)$ \\
\hline & Partial response & $87(55.1 \%)$ \\
\hline & Stable disease & $31(19.6 \%)$ \\
\hline & Progressive disease & $15(9.5 \%)$ \\
\hline $\begin{array}{l}\text { Definitive Concurrent } \\
\text { chemoradiotherapy } \\
\text { (CCRT) }\end{array}$ & & $n=229$ \\
\hline \multirow[t]{4}{*}{ CCRT regimen } & Weekly cisplatin & $133(58.1 \%)$ \\
\hline & 3-weekly cisplatin & $63(27.5 \%)$ \\
\hline & Fluorouracil + Cisplatin & $22(9.6 \%)$ \\
\hline & Others & $11(4.8 \%)$ \\
\hline $\begin{array}{l}\text { Total radiation dose } \\
\text { (Gy) }\end{array}$ & $\begin{array}{l}\text { Mean: } 62.5 \text { / Median: } \\
67.5 \text { Gy }\end{array}$ & Range $32-72$ \\
\hline \multirow{4}{*}{$\begin{array}{l}\text { Best overall } \\
\text { response }\end{array}$} & Complete response & $148(65.2 \%)$ \\
\hline & Partial response & $42(18.5 \%)$ \\
\hline & Stable disease & $21(9.3 \%)$ \\
\hline & Progressive disease & 16 (7.1\%) \\
\hline
\end{tabular}

oropharynx), advanced $\mathrm{T}$ and $\mathrm{N}$ classification, and inadequate treatment (vs. CCRT) were independent predictors for poor survival (Table 3, Supplementary Table 3).

\section{Discussion}

This nationwide retrospective cohort study including 445 patients with LA-HNSCC found that $87 \%$ of the patients received multimodality treatment modalities. Based on treatment intents, $52 \%$ of the patients received definitive CCRT, while $42 \%$ underwent surgery. Approximately $36 \%$ of the study population received IC. Regarding multidisciplinary approaches, the preferred treatment strategy was definitive CCRT in $28 \%$, IC then definitive CCRT in $23 \%$, surgery followed by adjuvant CCRT in $14 \%$ or adjuvant radiotherapy in $14 \%$ of the patients. Overall outcomes for one- and two-year survival rates were 88.7 and $79.8 \%$, respectively.

In the context of LA-HNSCC therapeutics, our study provides valuable information for drawing a general treatment landscape. OS was not different between definitive the CCRT and surgery groups. Given that IC was administered in approximately one-third of our patients with more advanced disease, IC did not show survival advantages in either the CCRT or surgery group. Though a recommendation for IC, except for the purpose of laryngeal preservation, has yet to be established, [7-9] only $19 \%$ of our patients with laryngeal cancer received IC. In other words, the real-world practice indicated that IC was being performed more actively for 


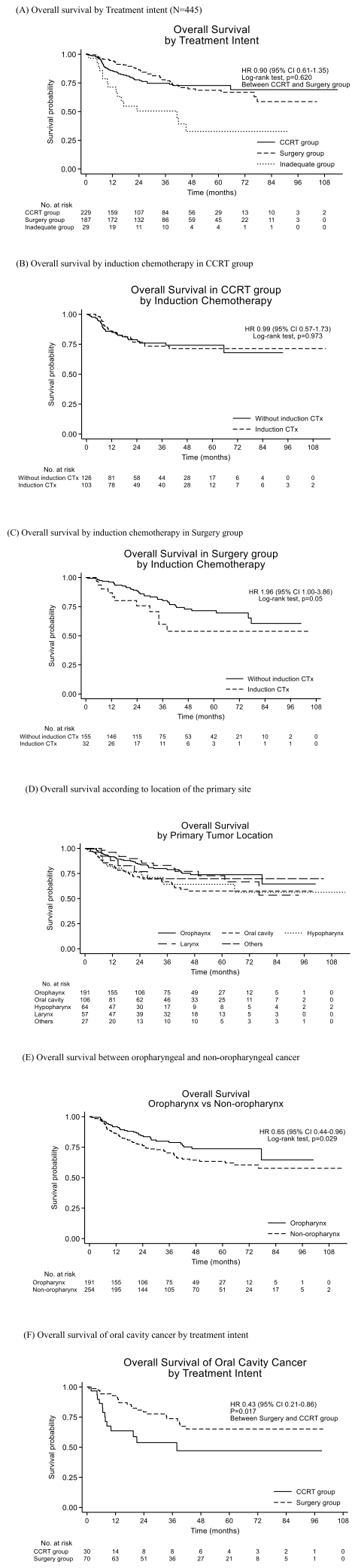

Fig. 2 a Overall survival by Treatment intent $(N=445)$. b Overall survival by induction chemotherapy in CCRT group. c Overall survival by induction chemotherapy in Surgery group. d Overall survival according to location of the primary site. e Overall survival between oropharyngeal and non-oropharyngeal cancer. $\mathbf{f}$ Overall survival of oral cavity cancer by treatment intent

advanced stages of LA-HNSCC other than laryngeal cancer without definite evidence of its survival advantages. The patients receiving IC prior to surgery showed poorer OS than the patients receiving surgery without IC. The reason is that IC was performed when the tumor is bulky, and node is advanced (Supplementary Table 1). Approximately 23 patients (5\%) recognized in Fig. 1 did not receive subsequent definitive treatment after IC and showed the worst OS (Fig. 2a). Residual toxicity following IC could complicate succeeding definitive treatments, especially surgery, so physicians need to be more cautious in selecting the sequence of treatment modalities. In oral cavity cancer, which had the worst survival outcome, the surgical approach showed survival benefits over CCRT in our study. These results provide us valuable insights to build the optimal treatment strategy in oral cavity cancer.

Based on the TAX-323/EORTC-24971 and TAX-324 phase III trials, the TPF regimen as IC is now accepted to be an evidence-based regimen of choice [10-12]. This is because the TPF regimen proved clear survival benefits over FP chemotherapy in unresectable LA-HNSCC [13]. Regarding toxicities, almost $80 \%$ of the patients treated with TPF regimen experience grade 3-4 neutropenia and $12 \%$ developed infection. Poor compliance (about $75 \%$ of patients completed the protocol) due to toxicities was another concern for the TPF regimen. In our study, DP was the most frequently administered regimen. For toxicity and adherence concerns, DP may be considered the preferred regimen in Korea instead of TPF [14, 15]. Given that there is currently no direct study comparing outcomes the DP and the TPF regimens, further research regarding optimal IC regimens is needed.

CCRT with cisplatin remains the gold standard for the treatment of LA-HNSCC [16]. In our LA-HNSCC population, definitive CCRT was the main therapeutic modality for more than half (52\%) of the patients. Regarding the schedule of cisplatin during definitive CCRT, weekly cisplatin was used approximately two times more frequently than 3 -weekly schedule ( $58 \%$ vs. $28 \%$ ). In a recent meta-analysis, Szturz et al. found that both highand low-dose cisplatin regimens yield similar survival outcomes for postoperative and definitive CCRT [17]. This finding is consistent with a population based study of US military veterans that included over 2900 patients 
Table 3 Patients and tumor characteristics related to progression-free survival and overall survival according to multivariate analysis

\begin{tabular}{lll}
\hline Outcomes & Estimate $(95 \% \mathrm{Cl})$ & $\boldsymbol{p}$-value \\
\hline Progression-free survival & Hazard ratio & $<0.001$ \\
Primary location (Others vs. Oropharynx) & $3.65(1.77-7.52)$ & 0.011 \\
T classification (from one unit to next) & $1.43(1.09-1.89)$ & 0.009 \\
Treatment strategy (Inadequate vs. CCRT) & $2.28(1.23-4.20)$ \\
Overall survival & $0.29(0.14-0.63)$ \\
HPV status (Positive vs. Negative) & $1.82(1.22-2.71)$ \\
Primary location (Oral cavity vs. Oropharynx) & $1.30(1.08-1.57)$ \\
T classification (from one unit to next) & $1.58(1.20-2.08)$ & 0.002 \\
N classification (from one unit to next) & $2.31(1.35-3.97)$ & 0.003 \\
Treatment strategy (Inadequate vs. CCRT) & 0.006 \\
\hline
\end{tabular}

CCRT Concurrent chemoradiotherapy, HPV Human papillomavirus

[18]. Given that 3-weekly cisplatin was associated with significantly more toxicity than weekly -cisplatin, tolerability is a key factor in selection. Preference for weekly cisplatin in our study reflects the physicians' tendency to value safety $[19,20]$. For postoperative CCRT in high-risk disease, a recent phase III study, conducted at a single institution in India, demonstrated that two-year locoregional control was superior in patients receiving $100 \mathrm{mg} / \mathrm{m}^{2}$ cisplatin every 3 weeks compared with $30 \mathrm{mg} / \mathrm{m}^{2}$ cisplatin weekly (73.1\% vs. $58.5 \%, p=0.014$ ) [6]. Because 3-weekly cisplatin results in more toxicity than weekly cisplatin, physicians need to choose a treatment regimen that balances efficacy with toxicity.

Our multivariate analyses demonstrated that positive HPV status was a good independent prognostic factor, consistent with other studies [21-23]. However, these results should be interpreted carefully, because the status of HPV infection was tested for only $43 \%$ of the patients and the prognostic role of HPV status in nonoropharyngeal cancer is inconclusive [24]. In particular, oral cavity cancer conferred the worst survival. Therefore, special attention to improve outcome in oral cavity cancer is warranted.

Several limitations to our study need to be addressed. First, data for this outcome study was collected and analyzed retrospectively, which has inherent selection bias. However, a relatively large number of LA-HNSCC patients $(n=445)$ were evaluated from thirteen nationwide referral hospitals, which represented a real-world situation in Korea. It will certainly be considered that the number of patients in our study is not sufficient to draw a definitive conclusion. Second, heterogeneous patients with tumor arising from various sites received different therapeutics. This limits the accurate interpretation of the study results. Lastly, our study could not collect toxicity profiles due to the risk of underestimating the retrospectively collected data.

\section{Conclusions}

Most patients with LA-HNSCC were treated with combined multidisciplinary therapeutics and showed favorable survival outcomes. Definitive CCRT, IC then definitive CCRT, and surgery followed by adjuvant CCRT or radiotherapy are the preferred multidisciplinary strategies. Though one-third of the patients received IC, its clinical role should be further evaluated in clinical trials. Our results are essential to understanding the patterns of multidisciplinary team approaches in real-world practice and to provide valuable insights regarding optimal therapeutic strategies for physicians. Prospective data is still needed to better assess therapy modalities in LA-HNSCC.

\section{Supplementary information}

Supplementary information accompanies this paper at https://doi.org/10. 1186/s12885-020-07297-z.

Additional file 1: Figure S1. Overall survival according to each treatment. Table S1. Demographics by receiving induction

chemotherapy. Table S2. Univariate and multivariate analyses for progression-free survival in 445 evaluable patients with LA-HNSCC. Table

S3. Univariate and multivariate analyses for overall survival 445 evaluable patients with LA-HNSCC.

\section{Abbreviations}

HNSCC: Head and neck squamous cell carcinoma; LA: Locally advanced; CCRT: Chemoradiotherapy;i IC: Induction chemotherapy; CT: Computed tomography; MRI: Magnetic Resonance Imaging; PFS: Progression-free survival; OS: Overall survival; CR: Complete response; PR: Partial response; PD: Progressive disease; HPV: Human papilloma virus

\section{Acknowledgements}

The research was supportive (in part) by the Korean Cancer Study Group and KCSG data center (CRA name: Jiyun Mun).

\section{Authors' contributions}

Conception and design: YGL, EJK, BK, HJY; Principal investigators of the study: $B K, H J Y$; Revision of study design and protocol: YGL, EJK, BK, HJY; Study coordination: YGL, EJK; Acquisition of data and patient recruitment: BK, JHC, JSK, KUP, KEL, JHK, KWL, MKK, HKA, SHS, HRK, SBK, HJY; Statistical analysis and data interpretation:. YGL, EJK, BK; Obtaining funding and supervision: BK, HJY; Drafting the manuscript: YGL, EJK; Revision of, adaptation of and final 
approval of manuscript: All authors; Accountable for all aspects of the work: All authors.

\section{Funding}

Study was supported by a grant from the National R\&D Program for Cancer Control, Ministry of Health and Welfare, Republic of Korea (HA16C0015). The funder had no role in the study design; in the collection, analysis and interpretation of data; in the writing of the report; or in the decision to submit the article for publication.

\section{Availability of data and materials}

Data would be available from the corresponding author on reasonable request.

\section{Ethics approval and consent to participate}

This study was approved by the ethics committee of Seoul National University Hospital (IRB-H-1304-089-481) and each participating hospital: Ajou University Hospital (AJIRB-MED-MDB-13-154); SMG-SNU Boramae Medical Center (26-2013-55); Keimyung University Dongsan Medical Center (201309-025); Ewha Womans University Hospital (2015-03-005); Kangdong Sacred Heart Hospital (13-2-31); Seoul National University Bundang Hospital (B1308-216-103); Yeungnam University Medical Center (YUH-13-0408-O47); Gachon University Gil Medical Center (GBIRB2015-169); Kosin University Gospel Hospital (13-090); Yonsei Cancer Center (4-2013-0363); Asan Medical Center (2013-0598); Chungnam National University Hospital (2013-10-003). And each Institutional Review Board approved the waiver of written informed consents because of the retrospective nature of this study.

\section{Consent for publication}

Not applicable.

\section{Competing interests}

The authors of this manuscript declare no relationships with any companies, whose products or services may be related to the subject matter of the article.

\section{Author details}

'Department of Internal Medicine, Kangbuk Samsung Hospital, Sungkyunkwan University School of Medicine, Seoul, Republic of Korea. ${ }^{2}$ Department of Internal Medicine, Korea University Guro Hospital, Seoul, Republic of Korea. ${ }^{3}$ Department of Internal Medicine, Seoul National University Hospital, 101 Daehak-ro, Jongno-gu, Seoul 03080, Republic of Korea. ${ }^{4}$ Department of Hematology-Oncology, Ajou University Hospital, Suwon, Republic of Korea. ${ }^{5}$ Department of Internal Medicine, SMG-SNU Boramae Medical Center, Seoul, Republic of Korea. ${ }^{6}$ Department of Hemato-Oncology, Keimyung University Dongsan Medical Center, Daegu, Republic of Korea. ${ }^{7}$ Department of Hematology and Oncology, Ewha Womans University Hospital, Seoul, Republic of Korea. ${ }^{8}$ Department of Internal Medicine, Hallym University College of Medicine, Kangdong Sacred Heart Hospital, Seoul, Republic of Korea. ${ }^{9}$ Department of Internal Medicine, Seoul National University Bundang Hospital, Seongnam, Republic of Korea. ${ }^{10}$ Department of Hematology-Oncology, Yeungnam University Medical Center, Daegu, Republic of Korea. ${ }^{11}$ Department of Internal Medicine, Gachon University Gil Medical Center, Incheon, Republic of Korea. ${ }^{12}$ Department of Internal Medicine, Kosin University Gospel Hospital, Busan, Republic of Korea. ${ }^{13}$ Department of Internal Medicine, Yonsei Cancer Center, Yonsei University College of Medicine, Seoul, Republic of Korea.

${ }^{14}$ Department of Internal Medicine, Asan Medical Center, University of UIsan College of Medicine, Seoul, Republic of Korea. ${ }^{15}$ Department of Internal Medicine, Chungnam National University Hospital, 282 Munhwa-ro, Jung-gu, Daejeon 35015, Republic of Korea.

Received: 3 June 2020 Accepted: 12 August 2020 Published online: 27 August 2020

\section{References}

1. Colevas AD, Yom SS, Pfister DG, Spencer S, Adelstein D, Adkins D, Brizel DM, Burtness B, Busse PM, Caudell JJ, et al. NCCN guidelines insights: head and neck cancers, version 1.2018. J Natl Compr Cancer Netw. 2018;16(5):479-90.
2. Hong S, Won YJ, Park YR, Jung KW, Kong HJ, Lee ES. Community of Population-Based Regional Cancer R: Cancer statistics in Korea: incidence, mortality, survival, and prevalence in 2017. Cancer Res Treat. 2020;52(2):335-50.

3. Marur S, Forastiere AA. Head and neck squamous cell carcinoma: update on epidemiology, diagnosis, and treatment. Mayo Clin Proc. 2016;91(3):386-96.

4. Cohen EE, Karrison TG, Kocherginsky M, Mueller J, Egan R, Huang CH, Brockstein BE, Agulnik MB, Mittal BB, Yunus F, et al. Phase III randomized trial of induction chemotherapy in patients with N2 or N3 locally advanced head and neck cancer. J Clin Oncol. 2014;32(25):2735-43.

5. Lee YG, Oh S, Kimm H, Koo DH, Kim DY, Kim BS, Lee SS. Practice patterns regarding multidisciplinary Cancer management and suggestions for further refinement: results from a National Survey in Korea. Cancer Res Treat. 2017; 49(4):1164-9.

6. Fonseca E, Grau JJ, Sastre J, Garcia-Gomez JM, Rueda A, Pastor M, Lara MA, Navalon M, Berrocal A, Tisaire JL, et al. Induction chemotherapy with cisplatin/docetaxel versus cisplatin/5-fluorouracil for locally advanced squamous cell carcinoma of the head and neck: a randomised phase II study. Eur J Cancer. 2005;41(9):1254-60.

7. Ma J, Liu Y, Yang X, Zhang CP, Zhang ZY, Zhong LP. Induction chemotherapy in patients with resectable head and neck squamous cell carcinoma: a meta-analysis. World J Surg Oncol. 2013;11:67.

8. Paccagnella A, Ghi MG, Loreggian L, Buffoli A, Koussis H, Mione CA, Bonetti A, Campostrini F, Gardani G, Ardizzoia A, et al. Concomitant chemoradiotherapy versus induction docetaxel, cisplatin and 5 fluorouracil (TPF) followed by concomitant chemoradiotherapy in locally advanced head and neck cancer: a phase II randomized study. Ann Oncol. 2010;21(7): $1515-22$.

9. Kim R, Hahn S, Shin J, Ock CY, Kim M, Keam B, Kim TM, Kim DW, Heo DS. The effect of induction chemotherapy using Docetaxel, Cisplatin, and fluorouracil on survival in locally advanced head and neck squamous cell carcinoma: a meta-analysis. Cancer Res Treat. 2016;48(3):907-16.

10. Vermorken JB, Remenar E, van Herpen C, Gorlia T, Mesia R, Degardin M, Stewart JS, Jelic S, Betka J, Preiss JH, et al. Cisplatin, fluorouracil, and docetaxel in unresectable head and neck cancer. N Engl J Med. 2007; 357(17):1695-704.

11. Posner MR, Hershock DM, Blajman CR, Mickiewicz E, Winquist E, Gorbounova V, Tjulandin S, Shin DM, Cullen K, Ervin TJ, et al. Cisplatin and fluorouracil alone or with docetaxel in head and neck cancer. N Engl J Med. 2007;357(17):1705-15.

12. Blanchard P, Bourhis J, Lacas B, Posner MR, Vermorken JB, Cruz Hernandez JJ, Bourredjem A, Calais G, Paccagnella A, Hitt R, et al. Taxane-cisplatinfluorouracil as induction chemotherapy in locally advanced head and neck cancers: an individual patient data meta-analysis of the meta-analysis of chemotherapy in head and neck cancer group. J Clin Oncol. 2013;31(23): 2854-60.

13. Haddad RI, Posner M, Hitt R, Cohen EEW, Schulten J, Lefebvre JL, Vermorken JB. Induction chemotherapy in locally advanced squamous cell carcinoma of the head and neck: role, controversy, and future directions. Ann Oncol. 2018;29(5):1130-40.

14. Choi YJ, Chung J, Shin HJ, Cho GJ, Wang SG, Lee BJ, Cho BM, Kim DW, Kim $\mathrm{HJ}$, Lee WS, et al. Induction chemotherapy of docetaxel and Cisplatin for the elderly patients with squamous cell carcinoma of the head and neck. Cancer Res Treat. 2007;39(1):1-5.

15. Ock CY, Keam B, Lim Y, Kim TM, Lee SH, Kwon SK, Hah JH, Kwon TK, Kim $\mathrm{DW}, \mathrm{Wu} \mathrm{HG}$, et al. Effect of induction chemotherapy on survival in locally advanced head and neck squamous cell carcinoma treated with concurrent chemoradiotherapy: single center experience. Head Neck. 2016;38(2):277-84

16. locca O, Farcomeni A, Di Rocco A, Di Maio P, Golusinski P, Pardinas Lopez S, Savo A, Pellini R, Spriano G. Locally advanced squamous cell carcinoma of the head and neck: a systematic review and Bayesian network meta-analysis of the currently available treatment options. Oral Oncol. 2018;80:40-51.

17. Szturz P, Wouters K, Kiyota N, Tahara M, Prabhash K, Noronha V, Adelstein D, Van Gestel D, Vermorken JB. Low-Dose vs. High-Dose Cisplatin: Lessons Learned From 59 Chemoradiotherapy Trials in Head and Neck Cancer. Front Oncol. 2019;9:86.

18. Bauml JM, Vinnakota R, Anna Park YH, Bates SE, Fojo T, Aggarwal C, Limaye S, Damjanov N, Di Stefano J, Ciunci C, et al. Cisplatin every 3 weeks versus weekly with definitive concurrent radiotherapy for squamous cell carcinoma of the head and neck. J Natl Cancer Inst. 2019;111(5):490-7.

19. Kang MH, Kang JH, Song HN, Jeong BK, Chai GY, Kang K, Woo SH, Park JJ, Kim JP. Concurrent Chemoradiation with low-dose weekly Cisplatin in 
locally advanced stage IV head and neck squamous cell carcinoma. Cancer Res Treat. 2015;47(3):441-7.

20. Lee SY, Choi YS, Song IC, Park SG, Keam B, Yang YJ, Song EK, Lee HJ, Cho SH, Shim H, et al. Comparison of standard-dose 3-weekly cisplatin and lowdose weekly cisplatin for concurrent chemoradiation of patients with locally advanced head and neck squamous cell cancer: a multicenter retrospective analysis. Medicine (Baltimore). 2018;97(21):e10778.

21. Fakhry C, Westra WH, Li S, Cmelak A, Ridge JA, Pinto H, Forastiere A, Gillison ML. Improved survival of patients with human papillomavirus-positive head and neck squamous cell carcinoma in a prospective clinical trial. J Natl Cancer Inst. 2008;100(4):261-9.

22. Ang KK, Harris J, Wheeler R, Weber R, Rosenthal DI, Nguyen-Tan PF, Westra WH, Chung CH, Jordan RC, Lu C, et al. Human papillomavirus and survival of patients with oropharyngeal cancer. N Engl J Med. 2010;363(1):24-35.

23. Chung CH, Zhang Q, Kong CS, Harris J, Fertig EJ, Harari PM, Wang D, Redmond KP, Shenouda G, Trotti A, et al. p16 protein expression and human papillomavirus status as prognostic biomarkers of nonoropharyngeal head and neck squamous cell carcinoma. J Clin Oncol. 2014;32(35):3930-8.

24. Fakhry C, Westra WH, Wang SJ, van Zante A, Zhang Y, Rettig E, Yin LX, Ryan WR, Ha PK, Wentz A, et al. The prognostic role of sex, race, and human papillomavirus in oropharyngeal and nonoropharyngeal head and neck squamous cell cancer. Cancer. 2017;123(9):1566-75.

\section{Publisher's Note}

Springer Nature remains neutral with regard to jurisdictional claims in published maps and institutional affiliations.

Ready to submit your research? Choose BMC and benefit from:

- fast, convenient online submission

- thorough peer review by experienced researchers in your field

- rapid publication on acceptance

- support for research data, including large and complex data types

- gold Open Access which fosters wider collaboration and increased citations

- maximum visibility for your research: over $100 \mathrm{M}$ website views per year

At $\mathrm{BMC}$, research is always in progress.

Learn more biomedcentral.com/submissions 